Dr. A. Aguirre Sayago

\title{
La legislación sanitaria en Chile
}

\author{
(Conclusión)
}

24. HORA, para terminar con este párralo, diré que la obser23. vación fundamental que puede hacérsele es la vaguedad de los arlículos 119-120 que se refieren a los exámenes de ascenso del personal. Sin pretender llegar hasta detalles impropios de una ley. creo que se debió precisar mucho más el procedimiento de estas pruebas, ya que de su seriedad depende toda la eficiencia del servicio. Si ellas son meras fórmulas, aun suponiendo el Código inmejorable, se habría edificado en la arena.

El párrafo 2 (arls. 133-139) trata del personal que formará el Departamento Administrativo del servicio. Si éste fuera realmente eso, no tendría para qué estudiarlo: pero hay entre los cinco únicos funcionarios superiores - un secretario, un abogado. un ingeniero, un arquilecto y un demógrafo-tres que constituyen una verdadera novedad en su carácter administrativo. Creo que únicamente en Chile los departamentos de ingeniería y arquitectura sanitarias y el de demografia sanitaria dejan de ser reparticiones técnicas, como lo reclama el sentido común y lo confirman la lotalidnd de las leyes modernas que conozco.

para no referirme sino a uno solo de estos tres casos, tomado como ejemplo, diré que en esla ley el demógrafo no ne- 
La legislación sanifaria en Chile

cesita ser médico ni menos especialista: basta un sujeto cualquiera que sepa algo del ramo (art. 136). Cuando se conoce de cerca la importancia del médico demógrafo en unạ organización sanitaria, ya que sobre él recae la verificación y clasificación de los boletines de fallecimiento conforme a la nomenclatura; cuando se conocen las dificultades de las causas múltiples de defunción y su influencia en la seriedad y comparabilidad de las estadisticas: cuando se conocen veinte otras más de igual naturaleza perturbadora. es algo que causa asombro pensar que en una ley moderna puedan existir semejantes faltas técnicas y todavia en algo que es a la vez base e indice del servicio: dame fus cifras y el modo de recogerlas e interpretarlas y te diré lo que valen tus afirmaciones estadisticas, puede exclamar axiomáticamente la demografia sanitaria. Para terminar con este párrafo final del Libro I, diré que un arlículobien administrativo por cierto. como es el 246 de Disposiciones Generales-que señala el número de horas de trabajo de tales empleados, estimo que debió ir a continuación del 139.

\section{B. SEGUNDA PARTE}

Paso ahora al Libro II, que trata de la Policia Sanitaria y que está únicamente subdividido en títulos. sin duda para diferenciarlo del otro.

EI PRIMERO de éstos se refiere a la profilaxia de las enfermedades infecciosas (arts. 140-154).

Su muy importante arlículo inicial establece la declaración médica obligaforia, por escrito, en la forma que se disponga. de las cenfermedades contagiosas y peligrosas.. Desgraciadamente el Código no señala esta nueva división de las contagiosas que tiene, sin duda, su imporlancia; pero. prescindiendo de este detalle, diré que, precisamente en esta lisla de enfermedades declarables junto con las formalidades para declararlas, y la facción de las estadisticas correspondientes, es donde de una mirada puede juzgarse cualquiera ley sanilaria.

Ánora bien, en presencia de esta lamentable omisión. ¿qué 
puedo decir? ya que para salvarla no basta absolutamente la pequeña lisla de enfermedades declarables de pais a pais. que señala el Código Sanilario Panamericano, incorporado en esta ley por el arliculo 217. Porque dentro del concepto de profilaxia sanitaria, aquella lista, que contiene únicamente las enfermedades en su mayoria exólicas y trasmisibles al exterior por la via comercial, es sólo una parle del conjunto de enfermedades que un pais está obligado a hacer declarar para sus fines de profilaxia interior.

De manera, pues, que la omisión de estas enfermedades declarables subsiste en toda su desnudez, ya que si bien es cierto que el pais está obligado a comunicar ampliamente sus casos de cólera. peste bubónica, fiebre amarilla, etc., no por eso está en absoluto dispensado de conocer las demás enfermedades que lo diezman, tales como la tuberculosis, la sifilis. el paludismo, el cáncer, las otras venéreas y veinte más que una ley sanitaria. que pretende ser moderna, pudo y debió colocar en su lista de enfermedades declarables.

Todavia hay otra consideración imperiosa que obliga a enumerar estas enfermedades y es la del secrelo profesional impuesto por leyes anteriores y que, al tener que ser abolido para determinados casos, impone al mismo tiempo la adopción de medidas para salvaguardiarlo hasla donde sea compatible con las necesidades sanitarias. En la mayoria inmensa de las declaraciones. lo que importa es conocer rápidamente el caso y no el nombre del paciente.

Si no se procede en esta forma, la experiencia mundial muestra que la declaración de las enfermedades está llamada a ser un fracaso.

En los articulos que siguen encuentro algunos dignos de comentario; tales son el 150, que impone a los padres o guardadores la obligación de volver a presentar los niños ante la autoridad a los ocho dias de vacunados. Estimando esla revisión muy beneficiosa. creo que se debió hacer algo más que estamparla en la ley y quizás proveer a su realización práclica con el establecimiento de algún aliciente material. Me parece que los 
chelines dados en Escocia o los francos dados en Bélgica, pueden ser un elocuente ejemplo.

Otro articulo de esta naturaleza es el 154 que finaliza el titulo: cuando parezca, dice, que existe la rabia entre los perros y ésta constituye amenaza, entonces se harán publicaciones, se describirá el área afectada. efc., elc.. y sólo entonces se advertirá a los dueños que deben abozalarlos. En suma, esto quiere decir que sólo después que haya un número suficiente de mordidos puede comenzar a funcionar sla advertencia. a los dueños.

Cómo se echa de ver en cada línea de las 15 que componen este largo artículo, el acendrado afecto a los perros. iCasi no se puede pedir mayor consideración y delicadeza para ellos! Sin embargo, para el perro urbano la experiencia demuestra que el bozal se impone obligatorio en paises de clima parecido al nuestro.

EL TítUlo II trala del ejercicio de la medicina y demás ramas del arle de curar (aris. 155-158).

En este sentido es apenas un esbozo e ignoro por qué se le dejó así y se prefirió anunciar una ley completa por el artículo 9 de que me ocupé al comienzo. En todo caso la ley que se dicle deberá ocupar esle sitio y refundirse con los pocos artículos que le perlenecen, como son la equiparación de las boticas y droguerias (art. 156) y la aulorización para ejercer de enfermero que dará mayor seriedad a esa carrera (art. 158). Algo que quizás pudiera agregarse a ésle, a manera de inciso, seria la facultad de retirar la autorización en casos determinados, como por ejemplo. faltas graves en el ejercicio profesional.

EL Título III trata de las drogas y arficulos alimenticios (arts. 157-166). 
Este tratamiento común para ambas cosas es una novedad y para el país un completo exotismo, desde que en las droguerías chilenas se venden únicamente drogas y no pasa como en ciertos paises europeos en que además se acude a ellas en busca de toda clase de comestibles y aún de ciertos articulos de menaje.

Testimonio de este antiguo uso es la ley análoga, el Foods and Drugs Act de Gran Bretaña, que es casi centenaria.

Dejando a un lado este aspecto del asunto, he tratado de estudiar las ventajas de esta reunión, pero sólo he encontrado como consecuencia de ella el que casi lodos los arlículos de este titulo adolecen de falta de claridad. Así, por ejemplo, el 159 y el 160. que delerminan las condiciones para fijar normas -a pesar de su redacción amplia-es evidente que sólo se refieren a ciertos alimentos susceplibles de tolerarlas (leche, grasa, etc.) y no a todos en general ni menos a las drogas cuyas normas están fijadas en la Farmacopea.

Los articulos 162, 163 y 164, que señalan las condiciones para repular lalsificados una droga o un alimento. presentan una gran variedad de defalles dispositivos entremezclados, que los hacen difusos; y todavia más, el 162 inciso 3 c está coınprendido en el 163; ésle. a su turno, está repelido para los alimentos bajo el 2 b del 164 y para las drogas por el 3 a del mismo: el 4 de este último está fuera de sitio y comprendido parcialmente en los anteriores, etc., etc.

Otros articulos, como el 165 , son un verdadero galimatias en el que se declara que la autoridad scada vez que lo solicite (?) entregará a su propia oficina de análisis las drogas aque deseare importars (?) y snotificará al dueño, (?) para que scomparezca ante aquéllas, éc. ¿Entiendes. Fabio?

Otros son pueriles, como el 166 , que prohibe la publicación de avisos referentes a smedicamentos o drogas siempre que no se indique su composiciónっ: pues si con esla medida se trala de evitar el desvergonzado reclamo comercial de productos desprovistos de acción curadora, pero con muchísima para explotar 


\section{La legislación sanitaria en Chile}

la ignorancia del público. tal obligación no constituye impedimento alguno para ello.

Otros aun son peligrosos, como la disposición 1 del 162, que permite evender drogas de menos polencia, calidad o pureza qué las señaladas en la Farmacopeas, siempre que se indiquen éslas claramente; pues con ella se abre la puerla al abuso, ya que el $95 \%$ de la clientela de las larmacias no liene conocimientos para poder discernir en el caso dado.

Las dos observaciones que sugiere este articulo son: $10^{\circ}$ que todo lo que se refiere a drogas deberia estar incluido en el párrafo que trate de las boticas y droguerias; $2 .^{\circ}$ que en lo referente a los alimentos, las bebidas son apenas mencionadas y. lo que es más lamentable, para ellas no hay ni un modesto artículo en que se hubiera visto siquiera la intención de los legisladores de ayudar a la lucha antialcohólica.

Finalmente, a modo de comentario general decisivo de este título. diré que he querido estudiarlo en detalle y con toda seriedad a pesar de que conozco su origen; pero lo he hecho para demostrar en forma fehaciente los puntos que calza el procedimiento de los legisladores. pues casi la totalidad de este título es la copia literal de ciertas bases, más o menos mediocres, presentadas por el Dr. Cronin a la VII Conferencia Danamericana, y en cuyo encabezamiento se hace especial hincapié en que la redacción de ellas sno debe tomarse en ningún caso como articulos de un proyecto de ley, sino como suna simple guía. para la confección de una adecuada a cada pais, de acuerdo con sus sconstituciones respectivas, las leyes vigentes y aủn las otras circunslancias que rodeen el asunto. .

De donde se deduce que aun para copiar hay que saber hacerlo, y más aún cuando parte de las confusiones estudiadas provienen de las alteraciones hechas al lexto original.

Después de esto, y en presencia de la sobria elocuencia del hecho en sí mismo, me parece que toda palabra más es superflua. 
El TíTULO IV trata del mâs apasionante problema social (articulos 167-171).

El primero de éslos dice: sprohibese el ejercicio de la prostifución, y para reforzarlo prohibe igualmente su fomento en cualquier forma. Los siguientes indican las contravenciones que serân castigadas con multas (168). conceden acción popular para denunciarlas (169), distribuyen el $50 \%$ de la multa entre los agentes denunciantes (170) y. finalmenle el último, señala el castigo del falso denunciador.

Alabo, como el que más, el nobilisimo intento que por primera vez ha escrito la disposición del artículo 167 en una ley chilena. Pero, al mismo tiempo, me asombran su laconismo y, ¿por qué no decirlo?. su ingenuidad; pues creo que lo es el haber pensado que con escribir tres palabras ha quedado resuelto uno de los más formidables problemas éticos. Su laconismo, porque cuando recuerdo todas las consideraciones guardadas a los perros (art. 154). me apena el pensar que no se tuvo siquiera igual crilerio para legislar acerca de esas mujeres que forman aquel triste rebaño humano.

Digo esto, porque debo precisar que el combate contra la prostitución no es un sencillo asunto de delincuencia como erradamente, a mi juicio. lo considera esta ley, sino que, por el contrario, es un complejo capítulo de patologia social y médica en que la prostitución es efecto y no causa.

¿Dónde eslán los minuciosos estudios etiológico-sociales acerca de la población del vicio?

¿Se ignora acaso que muchas de esas infelices son débiles mentales y que la totalidad de ellas son enfermas más o menos contagiosas?

¿Y todavia más. se ha pensado asimismo qué deberá hacerse con cierto número de esas mujeres, al suprimir para ellas la única manera de ganar el pan, pues jamás han sabido de otra. mientras adquieren una manera honrada? 
Si realmente se trata de resolver el problema y no de mistificar a la opinión pública, ¿dónde están los medios-asilos, reformatorios, hospitales, elc., capaces de obtener la reintegración de la mayor parle de esa gente a la Sociedad en calidad de miembros útiles? ¿Dónde está o se formará el personal adecuado para tales medios y quién decidirá el conjunto de medidas cuya aplicación ajustada conducirá al resultado perseguido?

La ley ha omitido todo eso y mucho más; sólo se preocupa del castigo de las infracciones al 167.

¿Qué clase de infracciones? Tampoco se pronuncia ella y supongo serán las que se refieren al ejercicio de la prostitución. pero ¿cómo se fendrá la evidencia de éstas? Los legisladores lo sabrán. ¿Se castigará igualmente a ambos coautores-porque si hay delito. éste es uno de los que no se pueden realizar sin ayuda-o se castigará únicamente a uno de ellos. con lo cual se demostraria, en forma desquiciadora, que se tiene una moralidad diversa para cada sexo? La ley no especifica tampoco el punto.

Ahora, la forma de castigo, la multa-especialmente señalada por la experiencia mundial como lo más inútil en este sentidoasciende de 500 a $1,000,2.000$ y 5.000 pesos. ¿Y si el delincuente no tiene dinero para poder pagar alguna de estas multas? ¿Se le reducirá entonces a prisión como en el caso definido por la ley para la $5 .^{\text {a }}$ reincidencia? Dero si la cárcel no ha sido jamás escuela de belleza o de bondad, y en este caso, en que se trata de rehabilitar socialmente al afectado. menos que en ninguno. ¿lgnoraban acaso esto los ligisladores? Puede que sí. cuando olvidaron que el trabajo es el único medio conocido, capaz de ejercer la doble acción correctiva y educadora que el caso necesitaba. Treinta, sesenta o más dias de reclusión en un establecimiento adecuado. corresponden ampliamente a cientos de miles de pesos en multas incobrables o virfuales, sin acción represiva alguna, y habrian sido bien la hisfórica onza de prevención, de que habla el viejo proverbio americano.

Finalmente. ¿cuáles serán los resultados de esta legislación? 
Desde luego uno moral, el hacer desaparecer ese baldón que era el burdel reglamentado por la autoridad (!): otro, malerial. la desaparición de la ecasa, colectiva para hacerla reaparecer en forma unipersonal. En cuanto a profilaxia, un cero, como antes.

Para cerrar el esfudio de este título, formulo solamente el deseo de que la disposición que pena la denuncia falsa (Art. 171) la que quiero suponer muy eficaz-sea pronto completada en la legislación no sanitaria con la penalidad del daño moral, para oblener que ambas unidas sean capaces de llegar quizás a impedir la perpetración de posibles villanos atentados a la honra ajena.

El título $V$ trata de los dementes (Aris. 172-182). En el primer artículo se comienza por la definición dél Manicomio del Estado., para dar en seguida la del edemente, que, según esta ley, es toda persona que presente perturbaciones en cualquiera de los grados y de las formas de su actividad mental.

En verdad no he podido comprender la necesidad de tales definiciones, especialmente de la última, la cual es de fal manera amplia, que si hubiera sido puesta para ceñirse a ella en los informes respectivos, nadie podria exceptuarse de ser declarado demente. Sino lo ha sido con este objelo, todavia es más dudosa su utilidad. pues es hecho conocido, aún de los legos. el que una de las lagunas de nuestra legislación civil es, precisamente, la anticuada clasificación de los enfermos mentales del Código de Bello.

Por otra parte, en presencia del progreso de la psiquiatria. creo que además es poco oporluna la elección de esle término -demente, que tiene en ella un significado definido y máxime cuando la ley misma comienza por no usarlo en sus arliculos. como el 182 y otros en que emplea el de sinsano. A mayor abundamiento puedo agregar que ni siquiera .Manicomio. es usado. pues en su reemplazo dice shospital de dementes, (Arts. 26. 181 y otros). 
No cabe duda que esle es un lujo que sólo el Estado puede darse: el crear una definición obligatoria para los demás y el poder prescindir de ella.

Los demás arlículos de este título que tratan del mecanismo de reclusión del insano, de cargo de quien deben ser los gastos en que ésle incurra, de los diferentes deberes del Defensor de Menores a su respecto y demás disposiciones pertinenles, quedan fuera de mi juicio por carecer de la preparación juridica necesaria. Ignoro si son dignos de alabanza, si están ya expresados o si por su contenido pertenecen con mejor titulo a otras leyes, efc., eic.

Pero si ese campo me está vedado. creo que los demás me son accesibles: y así, sin detenerme en la incógnila de la Dirección superior de los Manicomios del Estado, sólo quiero hacer una observación, que mostrará de nuevo el mismo descuido de siempre. El artículo 179 carece de conclusión lógica. Puede que esté incompleto. pero si no lo estuviese-por lo que se alcanza a descifrar de él-se trataria de la Facultad de pedir informes respecto del estado mental de alguien. Seria ésto una mera repetición del inciso $1 .^{\circ}$ del 173.

El Título VI trata de la entrada y registro en lugares cerrados (Arts. 183-187).

Por análoga circunstancia a la del caso anterior lamento no poder emilir una opinión completa: de manera que me limitaré tan sỏlo a algunas breves observaciones.

- Cuando fuere necesario para la debida aplicación de las leyes y ordenanzas., dice el articulo 183, se confiere eal Director General por sí o por delegado, poder epara entrar en cualquier edificio o lugar cerrado, con el fin de practicar inspecciones y registros; diligencia que, en general, deberá practicarse de dia: pero, que si lo fuere de urgencia. a cualquiera hora de la noche.

Sin pronunciarme acerca del alcance de lan dura medida sa- 
nitaria, creo que se debió haberla rodeado de un poco más de seriedad: quiero decir que sólo se hubiera podido llevar a cabo en virtud de una orden escrifa_como la requerida por la diligencia judicial análoga-basada aún en algo definido como, por ejemplo, la denuncia, igualmente escrita, de algún irritante atropello a claros preceptos de la ley. presentada por un funcionario del servicio y no en algo fan vago como aquello de sla debida aplicación.

Por otra parte el inciso $3 .^{\circ}$ del mismo articulo habla de urgencia, pero no define qué aclividades o circunstancias serán estimadas de esa naturaleza ni tampoco quién deberá calificarlas, omisiones ambas que, fuera de su importancia intrínseca, tienen todavia la del hecho de que en virtud de ellas la diligencia será nocturna.

Todavia, en el concepto de rodear a esta diligencia de las mayores garantias, creo que la ley debió de ponerse en el caso. desgraciado, de que ella pudiera ser aplicada con precipitación - sobre la base de datos y denuncios maliciosos. Para ello. quizás habria bastado declarar la responsabilidad del causante de la aplicación no justificada de una medida de tal magnitud.

Verdad es que dicha declaración es del todo inútil para los grandes centros urbanos, pero quizás no lo sea para aquéllos en el fondo de lejanas provincias. Para creerlo así, no basta. por ejemplo. recordar hasta qué punto la pasión politica puede extraviar, con criterio lugareño, aun a aquellas autoridades que parecen menos influenciables.

El articulo 184 sugiere una observación de naluraleza semejante a la última: manda, ésle, adoptar en los registros domiciliariós todas las medidas para guardar los secretos o no comprometer la repulación del interesado. IVaya un interesadol Se me ocurre que en dicho articulo falta un inciso que contenga la clasificación de la falta en que incurrirá el agente de la autoridad que divulgue tales pormenores de naturaleza reservada.

Una última observación la suministran los artículos 186 y 187 . El primero manda dar al interesado copia del inventario de los 


\section{La legislación sanifaria en Chile}

objetos que se recojan durante el registro y el siguiente precisa que si durante éste se comprobara una infracción podrá darse tal o cual destino a los elementos que hubieren servido para cometerla. Prescindiendo de que lógicamente el $186 \mathrm{de-}$ biera ir a continuación o mejor aún ser un simple inciso del 187. hay en el espíritu de ambos articulos base para sospechar cierta incertidumbre respecto a la finalidad real de los registros. ¿Persigue esta diligencia la debida aplicación de la ley? ¿Persigue únicamente la sorpresa del infractor? Los legisladores lo sabrán, a menos que ambos conceptos los tengan ellos por sinónimos.

El Título VII se ocupa de la Policia Morfuoria (Arts. 188-216). Aunque de por si es suficiente. circunstancia muy explicable en un país que cultiva la muerte. con las ampliaciones previstas en esta misma ley-las del embalsamamiento de los cadáveres y de las empresas funerarias a que se refiere el articulo 90-llegará a ser. como corresponde. el más completo de todo el Código.

En general, los articulos de este tilulo no tienen una distribución lógica y algunos de ideas muy conexas están fraccionados en varios articulos distantes. Asi. por ejemplo, en mi concepto el artículo inicial debió ser el 197. que fija la autoridad única del Director General en lo que se refiere al establecimiento y clausura de cementerios o de exhumaciones dentro de la República. A continuación, el 198 debería ser simple inciso del $1 .^{\circ}$. ya que se refiere al trámite de la solicitud del permiso correspondiente. Luego después, se debieron poner los arliculos 189 y 190 refundidos en uno solo, diciendo simplemenie que la $\mathrm{Di}$ rección General resolverá en cada caso de solicitud, previo estudio del terreno y de los antecedentes. Digo esto porque, de ambos, uno dice que no podrá estar un cementerio a menos de 25 metros de las viviendas, y el otro, que tampoco podrá 
estar a 50 de rios, manantiales, elc.; materias las dos que parecen más propias de reglamenlo que de ley.

Todavia, para darle aún mayor importancia al articulo hipotético que he formulado, estimo se le podría agregar a manera de inciso la idea secundaria contenida en el 188, que es el inicial de este tilulo, es decir. que en caso de urgencia la autoridad puede permitir las inhumaciones en lugares otros que los habituales.

Después de estos arlículos podrian seguir el 191, que establece delalladas normas para los cementerios municipales; el 192, que fija la inversión de ciertos dineros en ellos; el 193. que prohibe hacer en sus reglamenlos distinciones de raza, nacionalidad, etc. de los fallecidos o impedir el libre ejercicio de los sentimientos religiosos; el 195 y 196 refundidos, pues ambos se refieren a poder mejorar los existentes o crear nuevos mediante la ayuda de legados, etc., etc.

Estimo que el ejemplo, aunque largo, es demostrativo y todavia tiene la ventaja de permitirme aventurar la pregunta de si estos últimos arlículos-que son dignos de alabanza-no figurarian acaso con mejor derecho en la Ley de Municipalidades que en ésta.

Paso ahora a ocuparme del articulo 201. que trata de los cerfificados de defunción, asunto que es uno de los primordiales en toda ley sanitaria.

Por él se deja subsistente la doble siluación actual, o sea la del certificado expedido por el médico que en vida atendiera al difunto, o al testimonio de dos personas cualesquiera ante el respectivo oficial del Registro Civil. Además dicho artículo no precisa cuál es la autoridad a cargo del permiso de sepultar. la que sólo es definida por el 204 que, a mi juicio. debió de seguir a manera de inciso, porque en estas condiciones habría también desaparecido la ambigüedad de que adolece este artículo respecto a la designación de la constancia del fallecimiento y que debe ser dada por el Registro.

Creo inoficioso insistir en que, con el fin de tener las más fidedignas anolaciones de causas de muerte, en muchos paises 
se lucha actualmente, por todos los medios, para hacer desaparecer la fuente de la prueba testimonial, finalidad a la que, entre olras, ha prestado una gran ayuda la ley del seguro contra la enfermedad.

En cuanto al contenido del certificado médico mismo, el arlículo 202, como el anterior. restablece en detalle el actualmente en uso. Aunque pienso que dicha enumeración es propia del reglamento. su presencia en la ley es muy úfil, en este caso. para demostrar el anticuado carácter de tal certificado que no garantiza el secreto médico-base de las más verdaderas estadisticas de mortalidad-ni tampoco permite separar los datos que corresponden al Registro Civil de aquellos necesitados por la demografia sanitaria.

Para el primero basta anotar que la muerte de $N$. N., claramente individualizado, fué natural o no: para la segunda lo que importan son los datos personales de N. N., pero no su nombre. Tal es a lo menos el criterio de la Conferencia de Estadislica Sanitaria de Agosto último.

Pero todavia hay más: tanto el inciso único de éste. como el articulo siguiente, parecen mostrar. sin lugar a dudas, que hay una tercera manera de atestiguar un fallecimiento. ya que ambos dejan comprender que un médico de ocasión puede ser el llamado a expedir el certificado: dicen éstos. :que si el cadáver preseutase huellas de violencia o crimen, el médico (?) deberá especificarlas en su escrito., y, en conformidad a lo consignado más adelante al terminar el citado articulo 203, dar especialmente aviso de ello a la autoridad judicial.

Aunque no está claro que en este caso se trate únicamente del funcionario de sanidad local encargado entre. otras atenciones, de la correspondiente a esta labor (Art. 82 n), tanto en aquella disposición como en ésla no se manda proceder a la necropsia. Ahora bien, este sistema de certificar de oidas o por una simple inspección externa corporal la causa de un fallecimiento, es un sistema absolutamente inaconsejable, entre otras cosas, por su falacia estadistica, que lo coloca al nivel de la prueba testimonial. He aqui cómo en este nuevo caso. como en 
otros primordiales a las organizaciones sanitarias, el presente Código se demuestra demasiado conservador.

El Arliculo 206 define muy atinadamente las medidas que deberán observarse con el cadáver del fallecido de enfermedad infecciosa. De manera que el 215. que trala muy superficialmente la misma materia, no tiene mayor razón de existir y creo debe suprimirse.

Siguiendo el orden numérico debia mencionar ahora el 212; pero por referirse a obligaciones de las Juntas de Sanidad, fué estudiado en el párrafo respectivo.

El 214 es un articulo muy digno de atraer la atención, pero ignoro hasta qué punto lo sea de encomio. Define éste el orden relalivo en que corresponde a cónyuges, parientes e instituciones, el triste deber de dar sepultura. Me parece excelente y creo que, dada su redacción. Bello no lo habría desechado; pero me asaltan dudas acerca de la oportunidad de su presencia en una ley sanitaria.

El Arliculo 216 expresa que, si un cadáver no es reclamado, el Director General podrá destinarlo a fines médicos de investigación. Naturalmente que en la casi totalidad de ellos, se tratará de los fallecidos en las instiluciones públicas-asilos. hospilales, elc.

Estimo que para nuestro país, tan largo y con gente tan movediza, la ley debió en esla emergencia eslatuir el aviso previo practicado de varias maneras, sea por tarjetas circulares o avisos policiales a los deudos o personas indicadas al ingresar el paciente a los establecimientos, sea por publicación en la prensa diaria de los nombres de los fallecidos, sea por medio de carleles, elc. También debió la ley fijar un plazo de espera para el reclamo, el que por las circunstancias anteriores pudo ser de 36 o aún de 48 horas. Creo que lodo esto es asimismo un deber $y$. por otra parle, de esa manera se habrá facilitado la aplicación del arlículo 214 a que aludi inmedialamenle antes.

Para lerminar, quiero referirme, una vez más, al uso poco aconsejable de cierlas expresiones usadas indiferentemente en 
diversos artículos: por ejemplo. los números 205, 206, 215 emplean las de cenfermedades peligrosas y contagiosass: los 207 y 209 las de sinfecciosas y contagiosas: el 208 usa únicamente la expresión cinfecciosa». Quizás, como lo manifesté antes (Art. 140), hubiera habido ventaja en definir o unificar la terminologia.

El Título VIII trata de la Policia Marifima $y$ de las fronteras. Consta de un sólo artículo (217) por el cual se ratifica en todas sus partes, el Código Sanitario Marilimo Danamericano que, naturalmente, no se refiere a las fronteras terrestres.

Si desde el punto de vista de esta ley hubiera sido muy deseable que, en vez de injertar esa extensa recopilación, se la hubiese lomado de base para redactar los artículos pertinentes a este titulo y haber adquirido asi la homogeneidad y concisión de que carece, desde otros puntos de vista. tan amplia ratificación puede ser calificada de deplorable para los chilenos.

Para justificar este aserto me bastará recordar que el citado Código ordena crear (l) en Chile servicios que existen entre nosotros desde muchisimos años, tales por ejemplo. como el Registro Civil, que tiene ya cuarenta, o la Oficina Central de Estadistica, cuya reorganización sola bordea los veinte años. etc, orden ésta que es muy comprensible para aquellos paises que no los poseen o que poseyéndolos los tienen incompletos. como es el caso de Estados Unidos, que no logra tener el Registro Civil en todo su territorio.

De la misma manera el Código en cuestión ordena adoptar en nuestro pais la Clasificación de Causas de Muerle que precisamente con el volo de Chile fué declarada internacional en la conferencia de Paris en 1909 y que desde entonces es la empleada en nuestras estadísticas de mortalidad.

Todo eslo permile deducir que. si se juzgó procedente ratificar el Cödigo panamericano. y más aún, incluirlo en una ley chilena, se debió por lo menos ratificarlo con reservas. Si asi 
se hubiera procedido, se habría salvado también el pequeño incidente de que el pais aparezca en contradicción con opiniones antes sustentadas; ya que dicho Código ha venido a dar nueva vida a malerias que fueron rechazadas en la discusión de su homólogo internacional, aún pendiente, en el Office International d'Hygiène Publique de Paris, del que Chile es uno de los escasos miembros sudamericanos.

El TítUlo IX trata de la Salubridad de las poblaciones, pero a pesar de ello únicamente se ocupa de algo referente al agua potable y a los desagües.

En los dos únicos artículos de que consta se define la autoridad del Director General para todo lo pertinente a estos asuntos (218) y se prohibe descargar los desagües en posibles fuentes de agua para la bebida (219). lo que, desgraciadamente. es el caso de Santiago. El inciso prohibe, además, el empleo de las aguas servidas para ciertos usos agricolas, cosa que, en verdad, no basla prohibir sino que malerialmente hay que hacer imposible.

En suma, este titulo es apenas una pequeña fracción de lo que debió ser, si, esta ley, al igual de otras modernas, tal como la brasilera, hubiese creado una repartición técnica adecuada capaz de haber resuelto ampliamente esla parte del problema sanilario y de la cual, sin desmedro, habrian podido pasar a formar parte los excelentes acluales servicios del Estado en materia de aguas y desagües.

Espero que en descargo no se diga que para eso la Dirección General cuenta con un ingeniero sanitario (1). porque. fuera de ser ésle uno solo, sus funciones son meramente administrativas y de ninguna manera técnicas, como ya lo he señalado.

El título X (Arts. 220-229) trala de cierlos asuntos de ré- 
$\underline{\text { La legislación sanitaria en Chile }}$

gimen interior tales como nombramientos. licencias, etc., que en realidad no tienen importancia sanilaria. Si lo menciono es debido a circustancias como son. entre otras, la de recordar que a éste pertenece el arliculo 221 que estatuye el derecho a descanso anual de los empleados y que creo debe salir de acá para ir a continuación del 132 en el Título III \& 1. Por la inversa. a continuación del 220. cuyo inciso crea los empleados auxiliares, debe figurar el 242, que define su situación dentro del servicio y después el 241 que clasifica a todos los empleados (incluso los anteriores) en relación con las partidas fijas y variables del presupuesto. Todavía más. creo que debe figurar tambiên en este Titulo-aunque sea al fin del mismo-el 244. que ordena rendir fianza a lodo empleado que luese nombrado para tener fondos a su cargo. Estos tres articulos perlenecen a -Disposiciones Generales..

También debo recordar que el 226, que se refiere a los reemplazos por enfermedad u otras causas, es el articulo general que corresponde al muy completo 90. particular del $\$$. Por esto es sensible que en él, dado su carácler, se haya omitido el inciso que declara estos reemplazos sin derecho a remuneraciones adicionales.

El TíTULO XI (Arts. 230-239) se refiere a las penas aplicables a los infractores de la ley y al procedimiento de su aplicación. Como el anterior. tampoco tiene importancia sanitaria. y aunque juzgo que en él pudieran tener perfecta cabida también las sanciones que corresponden a los empleados miembros del servicio. sólo de paso deseo referirme a un artículo. el 237. que declara suficiente para comprobar una infracción a esta ley. el acta levantada por un funcionario de sanidad y alestiguada con dos empleados más del servicio. Considero que quizás este articulo es un tanto peligroso por los abusos a que se puede prestar y creo que. sin pronunciarme contra él, un inciso en que se señale el castigo a que se hacen acreedores aquellos que produjesen una acta falsa bastaria para corregirlo. 
El TítUlo XII, que es el último (Arts. 240 a 262) se deno. mina sisposiciones Generales,, nombre que, desgraciadamente, cuadra poco con su conlenido, ya que, excepción de dos articulos de los 23 que contiene y de algunos que con cierta tolerancia pueden dejarse figurar bajo tal rubro, los restantes pertenecen. sin lugar a duda, a los diversos titulos en que los he venido estudiando. Ejemplo de esta reclasificación es el caso de los números 243 y 259 . en que por tratarse de alribuciones del Director General lo han sido en el $\$ 1$ del Título I; el de los números 245, 247, 249 y 260, que se refieren al personal técnico o administrativo y que lo han sido igualmente en los $\S 1$ a 2 del Título III: el de los números 241, 242 y 244 , que clasifican a los empleados y que lo han sido en el Título X: el 258, que trata de medicinas y que completa al 93 en el $\$ 5 \mathrm{de}$ II; el 257. que se refiere a la atención médica de los presos y en verdad refunde los artículos 44 y 70 , etc., etc.

En cuanto al saldo, o sea aquellos articulos que con cierta tolerancia pueden estudiarse en esle titulo, un grupo único es Tormado por los números 250 a 255 que, en general, se refieren a las sanciones que pueden sufrir los empleados sanitarios de cualquier categoria y a las formalidades de su aplicación.

Esle conjunto, que tiene una grande importancia no sólo para robustecer el respeto al agente sanitario sino también para la más justa aplicación de la ley misma, estimo que es deficiente y vago y que, por lo tanto, es necesario comenzar por mejorarlo haciendo concordar sus disposiciones con las otras pertinentes en los diversos títulos, y en seguida completarlo en el sentido de establecer las categorias de faltas y de sus sanciones respectivas.

Ejemplos de lo primero-es decir, de falta de concordanciamuestra el arliculo 250. que parece dar a la declaración de culpabilidad de un empleado pronunciada por el Consejo de $\mathrm{Hi}$ giene, una importancia que no está de acuerdo con la de simple información que a ella le concede el artículo 30; y además el 251 


\section{La legislación sanifaria en Chile}

que, al enumerar las sanciones administrativas - fuera de sus erratas-omite entre éstas la suspensión temporal contemplada en el articulo 86: todavia el 252. que manda en forma más definida lo mismo que el 127. es decir. la necesidad de oir al Consejo de $\mathrm{Hi}$ giene y al culpado antes de aplicar la medida disciplinaria, doble uso que, en el § I-III me hizo optar por la supresión de este último articulo, etc., etc.

En cuanto a la gradación de las sanciones, basta recordar el 254 que faculta la disponibilidad, sin relacionarla con nada concreto, para demostrar su evidente necesidad.

Antes de cerrar el estudio de este titulo no es posible dejar de referirse a un articulo que en él descuella por su insignificancia, digna del más minucioso e ingenuo reglamento. Es éste el 245. que manda al Director General tener un sello para usar en los documentos. No puedo menos que pensár que con idéntico criterio pudo estamparse en la ley el uso de una pluma fuente o de un limplia-uñas.

\section{REFLEXIONES FINALES}

Llegado al término del penoso viaje a lo largo de esta desmañada ley. cabe ahora hacer las consideraciones de conjunto cuyos fundamentos creo haber suministrado en los respectivos titulos.

Comienzo por la forma literaria, o sea por el texto mismo de la ley. De los articulos que lo componen, una parte apreciable o repite el mismo concepto, o presenta una distribución caprichosa, o bien entre aquellos de ideas conexas, muestra faltas de concordancia o del sentido de la proporción. En cuanto a la gramática, no sale mejor parada. pues los atropellos al idioma no son escasos y los hay de todas magniludes: en algunos arficulos son de fal naturaleza que los hacen incomprensibles o. lo que es peor todavia, faltos de sentido común.

Benévolamente juzgado, dicho texto acusa, pues, descuidoquizás precipitación-en sus autores: y. mảs que el de una ley. parece el de un proyecto a media gestación que por accidente 
hubiera visto la luz. Mucho se alardea de progreso, pero el Código anterior-tan vilipendiado - nos ahorraba este triste espectáculo.

En cuanto a la parfétécnica, me limitaré sólo a recordar brevemente algunas de las diversas impresiones recogidas.

La Dirección de Sanidad que la ley llama pomposamente -generals. lo es sólo en el nombre, porque apenas regula parte de los servicios que en otras organizaciones eficientes la caracterizan. Su apoyo inmediato y principal el .Consejo de Higiene. en vez de serlo, es un simple adorno, demostrada su muy apreciable invalidez congénila.

La restante organización, en general. muestra una ausencia casi uniforme de estructura y como consecuencia de ella hay falta absoluta de coordinación, lanlo de lo creado entre si como con otros servicios más o menos afines coexistentes, y de los cuales es imposible prescindir en la labor sanitaria.

Al hablar de ésta, estimo que un sitio especial debió hacerse en la ley para la tuición de la ayuda privada, que entre nosotros ha luchado por resolver con sus solas fuerzas algunos urgentes-aunque aislados-problemas sanitarios de los muchos huérfanos de toda atención gubernativa. Hermoso ejemplo de esta son el Patronato de la Infancia, las Ligas y Asociaciones contra la tuberculosis, la Liga de Higiene Social y tantas otras meritorias instiluciones que poseen ya cierla eficiencia, pero que podrian tenerla aún mucho mayor si la autoridad sanitaria. dentro de sus dominios, les definiera su respectivo campo de acción. de tal manera que su labor en éstos. tanto en superficie como en hondura. llegase a ser en realidad la irreemplazable e inteligente cooperación que ella debe significar.

Este es ciertamente el verdadero justo medio del Estado que fiene el deber de encauzar la iniciativa privada en materia sanitaria y no de ignorarla como algunos pretenden ni mucho menos abandonarle cierto servicios que él está en la exclusiva obligación de suministrar.

Por lo que se refiere a ciertos otros aspectos fundamentales. aunque circunscritos. de las actividades sanitarias, como la de- 


\section{La legislación sanitaria en Chile}

claración de las enfermedades infecciosas. los cerfificados de fallecimiento y la organización de la demografía correspondiente, elc.. vuelvo a repetir que la ley eslá completamente anticuada.

En el asunto de la reglamentación de las profesiones u oficios relacionados con el arle de curar. se perdió la excelente oportunidad de tener en el Consejo de Higiene, como en su homólogo danés, la autoridad legal sanitaria encargada de velar por el correcto ejercicio de todas ellas, el que habría llegado a ser de esta manera el tribunal deontológico. o sea de Moral profesional, tantas veces reclamado por la opinión.

En cuanto a la reglamentación de drogas y alimentos, creo que más bien debo correr un velo sobre esa vergüenza.

En la lucha contra los grandes azotes populares. fuera de la embestida contra la prostitución. que es precaria desde el punto de vista profiláctico. no hay en esla ley nada concreto contra la tuberculosis, que ella sola nos causa más de la décima parte de todas nuestras defunciones: nada contra las afecciones venéreas cuya honda labor degenerativa es ocioso recordar: nada contra el alcoholismo que no les va en zaga en esa tarea nefasta, etc., etc. Si me he referido en primer término a la tuberculosis es porque deseo no ocurra en Chile lo que ha sucedido en varias partes, después de reformas sanitarias al estilo de éstas. Por cjemplo, las Filipinas, que en 1900 tenian sólo 187.5 por 10.000. de mortalidad por dicha causa, han visto elevarse progresivamente esta cifra hasta llegar en 1925 a $237.5 \times 10.000$ !

En lo que se refiere a la organización defensiva de nuestras fronteras, y prescindiendo de las condiciones de otro orden. nada hay en la ley, absolutamente nada. para las terrestres y si mucha clasificación de puertos, buques, elc. para las maritimas. Sin embargo en aquellas del norte $y$ oriente hay paludismo. Iepra, bubónica. tracoma, etc., y en las maritimas podemos tener hoy o mañana todas las plagas conocidas.

De la misma manera que nuestra dilatada costa. merced a oportunas medidas legales. se está poblando de puerlos modernos, Valparaiso, Antofagasta, elc., asi la ley sanitaria debió 
también de proveerlos de los servicios capaces de ejercer su policia higiénica en cada uno de ellos, porque de otra manera se llegaria al absurdo, dada nuestra configuración geográfica. de obligar a todos los barcos que arriben a nuestras playas a recaladas forzosas en un puerto único-ejemplo Arica-a veces fuera de su ruta, con los consiguientes atrasos, gastos y molestias para el comercio.

Lo más importante que se debe anolar al haber de esta ley es la supresión de las auloridades sanitarias municipales. muy oportuna, en estos tiempos. en los que hasta el modelo mundial las presenta en semi fracaso. Por lo demás creo que pronto las Juntas locales de Sanidad, que reemplazan a aquéllas, podrán desempeñar airosamente su labor, dado que nosotros tenemos una mayor educación comunal que la de olros paises afines que igualmente las poseen, y en los cuales estos organismos funcionan perfectamente: lestigo de ello son las 116 -Juntas, de Cuba, para no citar sino el más caracleristico.

Algo que igualmente debe figurar bajo este rubro, es la espléndida tentativa de tener buenos funcionarios de sanidad; desgraciadamente. la ley sólo contempló bien el aspecto económico, pero no así el técnico, pues olvidó crear las respeclivas Escuelas de especialización. ¿O acaso se juzgó en teoria que con sólo los altos sueldos bastaba para tener un buen servicio? Sin embargo, en la práclica, cuando el personal carece de facilidades para mejorar su preparación, estos no bastan para tener un servicio que pueda ser calificado de bueno.

En cuanto al problema de nuestros hospitales, qué puedo decir. sino que la ley lo elude a pesar de reconocer que estos no pueden ser peores, cuando prevé la necesidad de defender a sus desgraciados ocupantes.

¡Y pensar que este es, acaso por su extensión, el más formidable, vergonzoso y urgente de nuestros vacios sanitarios y que en la ley no existe ni siquiera la intención de acometer su mejoramientol

En resumen, pues, mi querido amigo, en vez de haber creado 
La legislación sanifaria en Chile

con esta ley un potente chorro de agua cristalina que hubiera derribado todos los antros donde se albergan nuestras causas de enfermedad y de muerte prematura, hemos adquirido, en cambio, una costosa e incómoda regadera que sólo salpica y embarra.

Ginebra. 25 de Febrero de 1926. 